\title{
Efficient electron injection in organic light-emitting diodes using lithium quinolate/Ca/Al cathodes
}

\author{
Sung Hyun Kim and Jyongsik Jang \\ School of Chemical and Biological Engineering, Seoul National University, Shinlim-dong, Kwanak-gu, \\ Seoul 151-742, Korea \\ Jun Yeob Lee ${ }^{a)}$ \\ Department of Polymer Science and Engineering, Dankook University, Hannam-dong, Yongsan-gu, Seoul \\ 140-714, Korea
}

(Received 16 May 2007; accepted 13 August 2007; published online 4 September 2007)

\begin{abstract}
Device performances of green devices with cathode structure of lithium quinolate (Liq)/Ca/Al were investigated and electron injection mechanism was studied using ultraviolet photoelectron spectroscopy. Power efficiency could be improved by $70 \%$ by using $\mathrm{Liq} / \mathrm{Ca} / \mathrm{Al}$ cathode structure due to efficient electron injection, and interfacial energy barrier lowering by $\mathrm{Liq} / \mathrm{Ca} / \mathrm{Al}$ metal cathode was observed. (C) 2007 American Institute of Physics. [DOI: 10.1063/1.2779105]
\end{abstract}

Organic light-emitting diodes (OLEDs) have been known for more than 20 years and they are promising as next generation displays for mobile appliances and television applications. They have several merits of wide viewing angle, wide color gamut, and short response time for various applications. However, their lifetime and power consumptions need to be improved further to compete liquid crystal display.

Power consumption is determined by driving voltage and current efficiency of OLEDs and many studies have been devoted to develop cathode structures because electron is a minor carrier in organic devices. $\mathrm{LiF} / \mathrm{Al}$ has been typically used as a cathode for OLEDs and it was useful to get low driving voltage. ${ }^{1-4}$ Similar cathode structures of $\mathrm{CsF} / \mathrm{Al}$, $\mathrm{MgF}_{2} / \mathrm{Al}$, and $\mathrm{BaF}_{2} / \mathrm{Al}$ have been reported and it was found that those cathode structures were effective to facilitate electron injection to organic layers. ${ }^{5,6} \mathrm{Li}_{2} \mathrm{O}$ and $\mathrm{Cs}_{2} \mathrm{CO}_{3}$ have also been studied and it gave low driving voltage and high current efficiency. ${ }^{7,8}$ In particular, $\mathrm{Cs}_{2} \mathrm{CO}_{3}$ was very effective as an electron injection layer in polymer OLEDs. Another class of electron injection material is organometallic complexes with reactive alkali metals such as Li. Several Li containing electron injection materials have been developed and one of the most well known Li complexes is 2-hydroxyquinoline lithium (Liq) which was reported by Schmizt et $a .^{9}{ }^{9}$ Its performance as an electron injection layer was comparable to $\mathrm{LiF} / \mathrm{Al}$ and the device performance was not so sensitive to electron injection layer thickness and it could be deposited at low temperature.

One efficient way to reduce the driving voltage is to use reactive metals such as $\mathrm{Ca}$ between $\mathrm{LiF}$ and $\mathrm{Al}$. Brown et al. reported $\mathrm{LiF} / \mathrm{Ca} / \mathrm{Al}$, and $\mathrm{CsF} / \mathrm{Ca} / \mathrm{Al}$, and electron injection from cathode to organic layer was enhanced by incorporating reactive $\mathrm{Ca}$, resulting in high efficiency in OLEDs. ${ }^{10} \mathrm{LiF}$ dissociation by reactive $\mathrm{Ca}$ was proposed in their works. Assuming $\mathrm{LiF}$ dissociation by $\mathrm{Ca}$, dissociation of $\mathrm{Li}$ complexes can be activated easily because bond energy in organometallic complexes is generally lower than that of ionic compounds such as LiF. Therefore, reactive metals can be very

${ }^{a}$ Author to whom correspondence should be addressed; FAX: 82-2-7092614; electronic mail: leej17@dankook.ac.kr effective in organometallic based cathode system as an interlayer and can facilitate electron injection from cathode to organic layer.

In this work, a cathode system of $\mathrm{Liq} / \mathrm{Ca} / \mathrm{Al}$ was developed and its device performances were compared with those of Liq/Al cathode. Current injection in the device was studied and electron injection in $\mathrm{Liq} / \mathrm{Ca} / \mathrm{Al}$ was investigated with ultraviolet photoelectron spectroscopy (UPS) according to thickness of each layer.

A device configuration of indium tin oxide (ITO)/ $N, N^{\prime}$-diphenyl- $N, N^{\prime}$-bis-[4-(phenyl- $m$-tolyl-amino)-phenyl]biphenyl-4, 4' -diamine (60 nm)/ $N, N^{\prime}-\operatorname{di}\left(1-\right.$ naphthyl)- $N, N^{\prime}$ diphenylbenzidine $(30 \mathrm{~nm}) / \mathrm{Alq}_{3}(50 \mathrm{~nm}) / \mathrm{Liq}(1 \mathrm{~nm}) / \mathrm{Ca}$ $(1 \mathrm{~nm}) / \mathrm{Al}(100 \mathrm{~nm})$ was used to study the effect of Ca interlayer on device performances. The thicknesses of $\mathrm{Ca}$ were 0 and $1 \mathrm{~nm}$. Deposition rate of $\mathrm{Ca}$ was $0.2 \AA / \mathrm{s}$ and $\mathrm{Al}$ was evaporated at a deposition rate of $2 \AA / s$. Current-voltageluminance characteristics of devices were measured with Keithley 2400 source measurement unit and PR650 Spectrascan ${ }^{\circledR}$ colorimeter (Photoresearch, Inc.). UPS spectra were obtained on a PHI 5700 spectrometer using standard He I $(21.2 \mathrm{eV})$ sources.

Liq is an organometallic compound with low deposition temperature and it can be useful as an electron injection material due to low binding energy between Li and hydroxyquinoline ligand. ${ }^{9}$ Assuming dissociation of Liq by metal deposition as reported in other studies, ${ }^{1-5}$ low binding energy of Liq indicates easy liberation of Li during cathode deposition in Liq system. In addition, the dissociation of Li can be facilitated by reactive metals such as $\mathrm{Ca}$ and it is expected that $\mathrm{Liq} / \mathrm{Ca} / \mathrm{Al}$ cathode system can give low driving voltage due to efficient electron injection.

To correlate the cathode structure with device performances, current density and luminance of $\mathrm{Liq} / \mathrm{Ca} / \mathrm{Al}$ were compared with those of Liq/Al. Figure 1 shows current density and luminance of Liq devices with and without $\mathrm{Ca}$ interlayer between Liq and Al. Current density and luminance were increased by more than twice by introducing a $\mathrm{Ca}$ interlayer between Liq and Al. The high current density in $\mathrm{Liq} / \mathrm{Ca} / \mathrm{Al}$ indicates efficient electron injection from cathode to $\mathrm{Alq}_{3}$ because the only difference between the two devices is electron injection structure. 


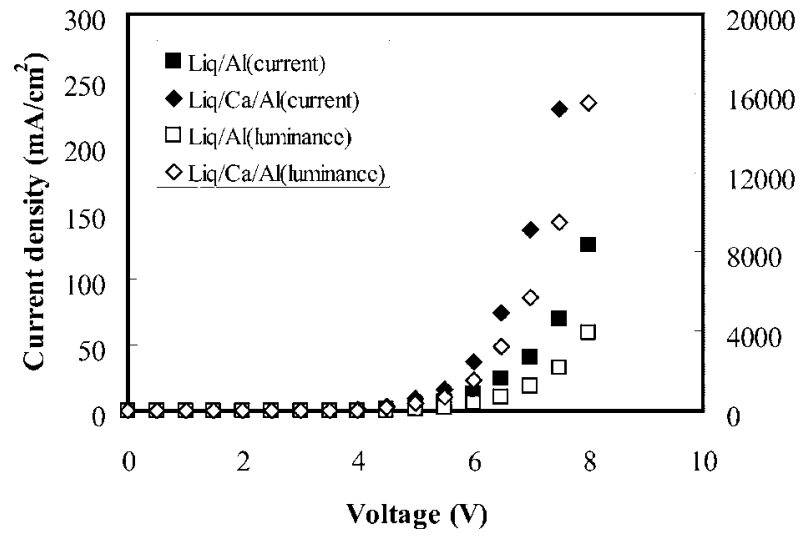

FIG. 1. Current density-voltage and luminance-voltage curves of Liq/Al and $\mathrm{Liq} / \mathrm{Ca} / \mathrm{Al}$ devices.

To study the change of interfacial energy barrier in $\mathrm{Liq} / \mathrm{Ca} / \mathrm{Al}$, in situ measurement of the highest occupied molecular orbital (HOMO) shift during deposition of $\mathrm{Ca}$ and $\mathrm{Al}$ was carried out. Figure 2 shows UPS spectra of Liq/ $\mathrm{Al}$ and $\mathrm{Liq} / \mathrm{Ca} / \mathrm{Al}$ according to the thicknesses of Liq, $\mathrm{Ca}$, and $\mathrm{Al}$. The binding energy was relative to the Fermi level and the onset of UPS spectra corresponds to HOMO or valence band. Assuming that the HOMO level shift induces the lowest unoccupied molecular orbital level lowering, the HOMO level lowering indicates reduced energy barrier for electron injection. It can be clearly seen that the $\mathrm{HOMO}$ level of $\mathrm{Alq}_{3}$ was

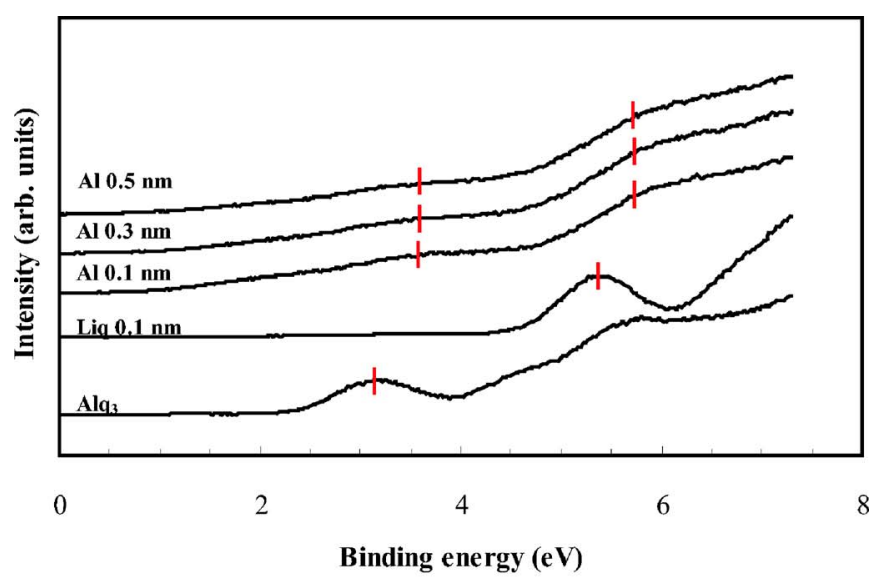

(a)

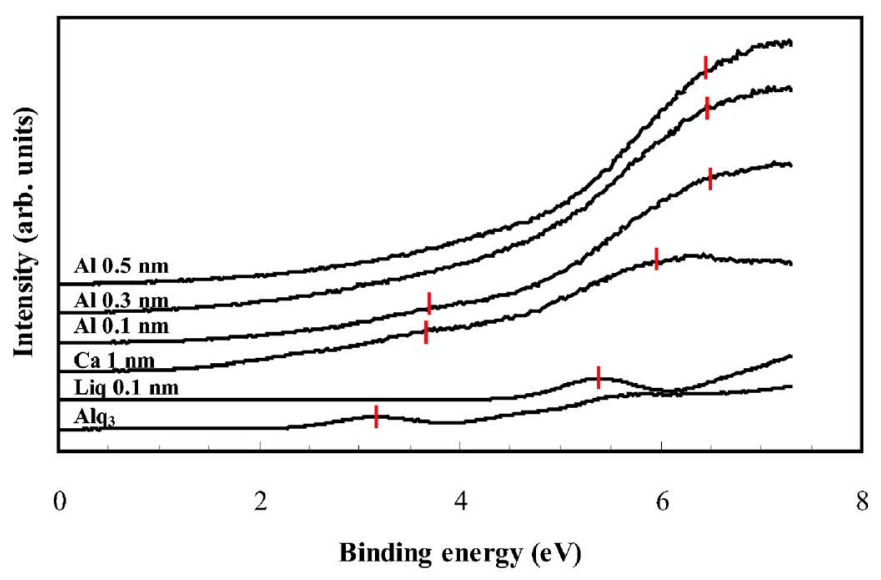

(b)

FIG. 2. (Color online) UPS spectra of $\mathrm{Liq} / \mathrm{Al}$ and $\mathrm{Liq} / \mathrm{Ca} / \mathrm{Al}$ according to thickness of metal layers; (a) Liq/Al and (b) Liq/Ca/Al.

Downloaded 23 Nov 2007 to 147.46.143.55. Redistribution subject to

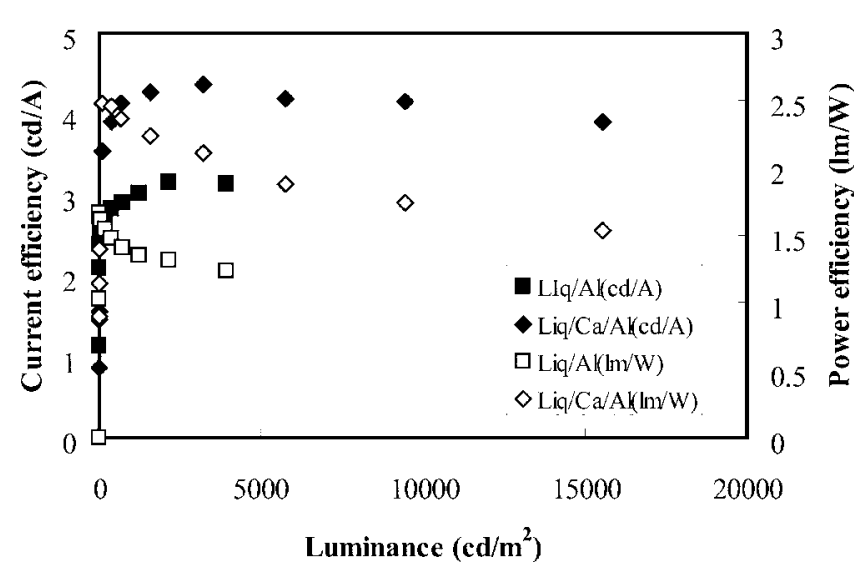

FIG. 3. Plot of current efficiency and power efficiency of Liq/Al and $\mathrm{Liq} / \mathrm{Ca} / \mathrm{Al}$ devices.

shifted from 3.2 to $5.4 \mathrm{eV}$ by depositing Liq on $\mathrm{Alq}_{3}$ at a thickness of $1 \mathrm{~nm}$. Additional HOMO level shift and gap state formation were observed during deposition of $\mathrm{Al}$ on $\mathrm{Alq}_{3} / \mathrm{Liq}$ film and the HOMO level was lowered up to $5.6 \mathrm{eV}$. Compared with Liq/Al devices, the HOMO level of $\mathrm{Liq} / \mathrm{Ca} / \mathrm{Al}$ was further lowered by $\mathrm{Ca}$ interlayer. Additional interfacial energy lowering by $\mathrm{Ca}$ was $0.5 \mathrm{eV}$ and it was shifted by $0.6 \mathrm{eV}$ after $\mathrm{Al}$ deposition. Total HOMO level change in $\mathrm{Liq} / \mathrm{Ca} / \mathrm{Al}$ was $3.3 \mathrm{eV}$ compared with $2.4 \mathrm{eV}$ of $\mathrm{Liq} / \mathrm{Al}$. This indicates that the electron injection barrier between cathode and $\mathrm{Alq}_{3}$ is lowered by using $\mathrm{Liq} / \mathrm{Ca} / \mathrm{Al}$ cathode structure and the high current density in Liq/Ca/ $\mathrm{Al}$ device can be explained by efficient electron injection from $\mathrm{Al}$ to $\mathrm{Alq}_{3}$ by lowered interfacial energy barrier. ${ }^{11}$ Gap state formation was similarly observed both in Liq/Al and $\mathrm{Liq} / \mathrm{Ca} / \mathrm{Al}$, and it can be concluded that the interfacial energy barrier lowering by $\mathrm{Liq} / \mathrm{Ca} / \mathrm{Al}$ is mainly responsible for the high current density in $\mathrm{Liq} / \mathrm{Ca} / \mathrm{Al}$ devices. The origin of the low interfacial energy barrier in $\mathrm{Liq} / \mathrm{Ca} / \mathrm{Al}$ devices is not clear from UPS measurement, but it might be related with high chemical reactivity of Ca. Even though there is no direct evidence for the efficient dissociation of Liq by $\mathrm{Ca}$, it can be indirectly postulated that Liq reaction with $\mathrm{Ca}$ can be effective considering Gibbs free energy formation for $\mathrm{Li}-\mathrm{CaF}_{2}$ and $\mathrm{Li}-\mathrm{AlF}_{3}$. Calculated Gibbs free energy for $\mathrm{Li}-\mathrm{CaF}_{2}$ formation from LiF-Ca is $-0.2 \mathrm{~kJ} / \mathrm{mol}$, while it is $332.1 \mathrm{~kJ} / \mathrm{mol}$ for $\mathrm{Li}-\mathrm{AlF}_{3}$, implying that $\mathrm{Ca}$ is more reactive than $\mathrm{Al}$ for the dissociation of $\mathrm{Li}$ compounds. ${ }^{12}$

Figure 3 shows current efficiency and power efficiency of $\mathrm{Liq} / \mathrm{Ca} / \mathrm{Al}$ devices compared with those of Liq/Al. Current efficiency and power efficiency of Liq devices were enhanced by $\mathrm{Ca}$ interlayer and high current efficiency of $\mathrm{Liq} / \mathrm{Ca} / \mathrm{Al}$ devices can be explained by efficient hole and electron recombination in light-emitting layer. In general, hole is a majority carrier in organic devices and more electron injection from cathode to emitting layer or less hole injection can improve charge balance in the light-emitting layer. In case of $\mathrm{Liq} / \mathrm{Ca} / \mathrm{Al}$, electron injection was greatly improved by a metal interlayer and hole-electron balance in $\mathrm{Alq}_{3}$ can be better after introduction of Ca interlayer. High current efficiency in Liq/Ca/ $\mathrm{Al}$ devices with high current density supports the explanation. Current efficiency of Liq devices was enhanced from 3.1 to $4.3 \mathrm{~cd} / \mathrm{A}$ by $\mathrm{Ca}$ interlayer. Power efficiency was even more improved than current efficiency and power efficiency of $2.3 \mathrm{~lm} / \mathrm{W}$ could be obtained in $\mathrm{Liq} / \mathrm{Ca} / \mathrm{Al}$ device compared with $1.37 \mathrm{~lm} / \mathrm{W}$ of standard o AIP license or copyright; see http://apl.aip.org/apl/copyright.jsp 
device. $70 \%$ improvement of power efficiency was observed in $\mathrm{Liq} / \mathrm{Ca} / \mathrm{Al}$ devices and high power efficiency of $\mathrm{Ca}$ devices is due to high current efficiency and low driving voltage of $\mathrm{Liq} / \mathrm{Ca} / \mathrm{Al}$ devices.

In summary, introduction of metal interlayer of $\mathrm{Ca}$ was effective to improve electron injection from cathode to $\mathrm{Alq}_{3}$ and high current efficiency could be obtained. Power efficiency of $\mathrm{Liq} / \mathrm{Ca} / \mathrm{Al}$ devices was improved by $70 \%$ due to efficient electron injection, and low electron injection barrier in $\mathrm{Liq} / \mathrm{Ca} / \mathrm{Al}$ device was responsible for efficient electron injection.

${ }^{1}$ L. S. Hung, C. W. Tang, and M. G. Manson, Appl. Phys. Lett. 70, 152 (1997).

${ }^{2}$ S. Shi and D. Ma, Appl. Surf. Sci. 252, 6337 (2006).

${ }^{3}$ H. Heil, J. Steiger, S. Karg, M. Gastel, H. Ortner, H. von Seggern, and M. Stoßel, J. Appl. Phys. 89, 420 (2001).

${ }^{4}$ M. G. Mason, C. W. Tang, L.-S. Hung, P. Raychaudhuri, J. Madathil, D. J. Giesen, L. Yan, Q. T. Le, Y. Gao, S.-T. Lee, L. S. Liao, L. F. Cheng, W. R.
Salaneck, D. A. dos Santos, and J. L. Bredas, J. Appl. Phys. 89, 2756 (2001).

${ }^{5}$ Y. Park, J. Lee, S. K. Lee, and D. Y. Kim, Appl. Phys. Lett. 79, 105 (2001).

${ }^{6}$ J. Lee, Y. Park, S. K. Lee, E.-J. Cho, D. Y. Kim, H. Y. Chu, H. Lee, L. M. Do, and T. Zyung, Appl. Phys. Lett. 80, 3123 (2002).

${ }^{7}$ T. Wakimoto, Y. Fukuda, K. Nagayama, A. Yokoi, H. Nakada, and M. Tschuida, IEEE Trans. Electron Devices 44, 1245 (1997).

${ }^{8}$ J. Huang, G. Li, E. Wu, Q. Xu, and Y. Yang, Adv. Mater. (Weinheim, Ger.) 18, 114 (2006).

${ }^{9}$ C. Schmitz, H. Schmidt, and M. Thelakkat, Chem. Mater. 12, 3012 (2000).

${ }^{10}$ T. M. Brown, R. H. Friend, I. S. Millard, D. J. Lacey, T. Butler, J. H. Burroughes, and F. Cacialli, J. Appl. Phys. 93, 6159 (2003).

${ }^{11}$ J. Lee, Y. Park, D. Y. Kim, H. Y. Chu, H. Lee, and L.-M. Do, Appl. Phys. Lett. 82, 173 (2003).

${ }^{12}$ D. D. Wagman, W. H. Evans, V. B. Parker, R. H. Schumm, S. M. Baily, I. Halow, K. L. Churney, and R. L. Nuttall, in Handbook of Chemistry and Physics, 67th ed., edited by R. C. Weast, M. J. Astle, and W. H. Beyer (Chemical Rubber Corp., Boca Raton, FL, 1986), D-50. 